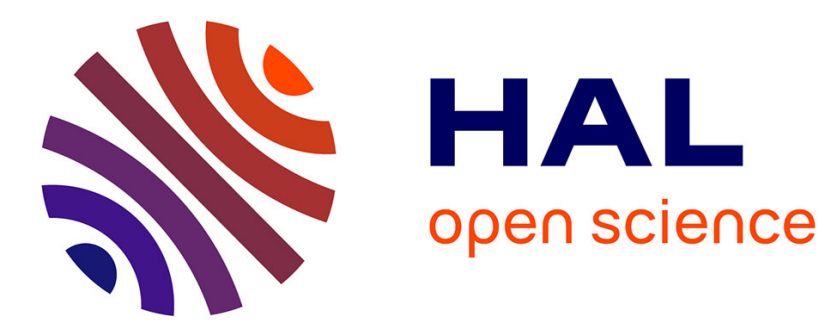

\title{
The Determination of the Equilibrium Exchange Rate in a Simple General Equilibrium Model
}

\author{
Cuong Le Van, Cécile Couharde, Thai Bao Luong
}

\section{To cite this version:}

Cuong Le Van, Cécile Couharde, Thai Bao Luong. The Determination of the Equilibrium Exchange Rate in a Simple General Equilibrium Model. 2004. halshs-03331130

\section{HAL Id: halshs-03331130 \\ https://shs.hal.science/halshs-03331130}

Submitted on 1 Sep 2021

HAL is a multi-disciplinary open access archive for the deposit and dissemination of scientific research documents, whether they are published or not. The documents may come from teaching and research institutions in France or abroad, or from public or private research centers.
L'archive ouverte pluridisciplinaire HAL, est destinée au dépôt et à la diffusion de documents scientifiques de niveau recherche, publiés ou non, émanant des établissements d'enseignement et de recherche français ou étrangers, des laboratoires publics ou privés. 

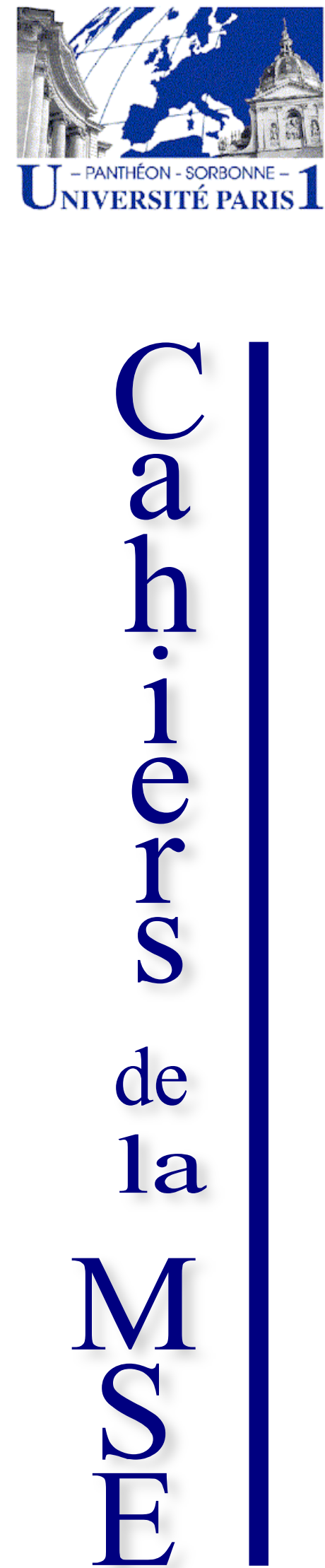

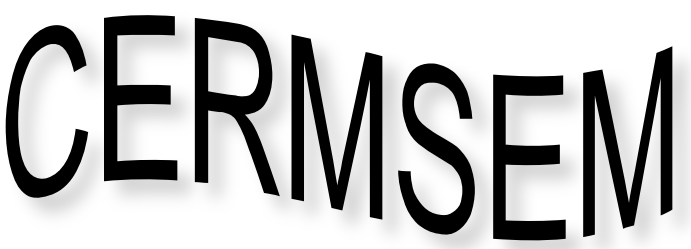

UMR CNRS 8095

The Determination of the Equilibrium Exchange Rate in a Simple General Equilibrium Model

\author{
Cuong Le VAN
}

Cécile COUHARDE

Thai Bao LUONG

2004.60 


\title{
The Determination of the Equilibrium Exchange Rate in a Simple General Equilibrium Model Cuong Le Van ${ }^{1}$, Cécile Couharde ${ }^{2}$, Thai Bao Luong ${ }^{3}$ \\ May 2004
}

\begin{abstract}
In this article, we develop an analytical general equilibrium model of the equilibrium exchange rate. This theoritical framework allows us to identify the relevant set of variables which determinate the equilibrium exchange rate and to explore how theses variables influence the trajectory of the equilibrium exchange rate.
\end{abstract}

Keywords: Equilibrium Exchange Rate, Purchasing Power Parity, BalassaSamuelson Effect, General Equilibrium Model.

\section{Introduction}

This paper is aimed at determining fundamentals of the equilibrium exchange rate (EER) for emerging countries and identifying the potential role they may play in explaining the trajectory of the EER.

Usually, equilibrium exchange rates are defined in reference to the purchasing power parity (PPP). PPP hypothesises that, over a given period of time, the percentage change in the nominal exchange rate between any two currencies will equal the difference between the percentage changes in the price levels of the two corresponding countries. However, this methodology has been discredited as an appropriate norm for defining equilibrium exchange rates of emerging countries, because of the Balassa effect (Balassa, 1964). This effect explains the tendency for catching up countries with higher productivity growth in tradables to undergo an appreciation of their real exchange rate (RER). That is why most theoretical approaches have been developed to explain deviations of the EER behaviour from PPP, assuming possible changes in fundamentals that could affect the EER. Such changes in fundamentals do matter in the context of emerging economies undergoing rapid structural transformation.

${ }^{1}$ CERMSEM, CORE, levan@core.ucl.ac.be

${ }^{2}$ CEPN,University Paris13,couharde@seg.univ-paris13.fr

${ }^{3} \mathrm{CEPN}$, University Paris 13,couharde@seg.univ-paris13.fr 
According to the typology proposed by Clark and MacDonald (1999), there are two main alternative approaches to PPP: the "Behavioural Equilibrium Exchange Rate" (BEER) approach and the "Fundamental Equilibrium Exchange Rate" (FEER) approach. The BEER approach covers a range of conceptual frameworks that focus simultaneously on long run equilibrium conditions for both asset stocks and current account flows (Stein 1994 ; Faruqee 1995). Such conceptual frameworks define the equilibrium levels or time paths of exchange rates as the levels or paths that give rise to current account flows that are consistent with convergence to long run asset stock equilibrium. At an empirical level, this approach leads to the estimation of single equation reduced-form models. Equilibrium exchange rates are then calculated as the fitted value of the real exchange rate when the fundamental variables take their long or medium term values. Whereas in the BEER approach the relevant notion of equilibrium refers to the long or medium term value of an appropriate set of explanatory variables, the FEER concept is based on the notion of macroeconomic balance, defined in terms of internal and external equilibria. Internal equilibrium is identified as a non-accelerating-inflation growth path. External equilibrium is defined by the sustainable net flow of resources between countries when they are in internal balance. Equilibrium exchange rates are calculated by using a complete macroeconomic model, in the general equilibrium approach proposed by Williamson (1985), or only the trade equations in a partial equilibrium approach (Wren-Lewis \& Driver, 1998; Borowski \& Couharde, 2002).

As these two approaches have been mainly developed for assessing equilibrium exchange rates of industrial countries, they are not entirely appropriate for analysing EER of emerging countries.

First, one problem is the Balassa effect, which is not represented in the main BEER models, nor in the FEER models. The reason is that the Balassa effect theoretically results from a partial equilibrium under severe assumptions (especially the law of one price for tradables), which do not fit the framework of the theoretical models cited above.

However, this problem does not yet exist at an empirical level. Most BEER estimates include the relative price of tradables to non-tradables or the differential in productivity between the tradable and non tradable sectors as a proxy of the Balassa effect. Moreover, the BEER approach has been extended to developing countries. Models implemented in this field are quite similar to that of industrial countries, except that the real exchange rate is defined in terms of the relative price of tradables to nontradables 
and can thus take into account explicitly the Balassa effect (Edwards, 1994; Elbadawi, 1994; Montiel, 1999). In the FEER approach, the assessment of equilibrium exchange rates is not also biased by the Balassa effect. Indeed, if an economy is in its internal and external equilibria at the base period and if there is some RER appreciation without degrading its external balance, this appreciation will not be identified as a real overvaluation. This situation can reflect the Balassa effect, in which some RER appreciation may occur without loss of competitiveness in tradables (Coudert \& Couharde, 2002).

An other problem raised by these approaches is the definition of the internal equilibrium. Internal equilibrium is generally defined on the basis of the potential growth rates estimated separately from the model. The internal equilibrium is thus exogenous to the model insofar as potential growth is assumed to be independent of the real exchange rate. Nevertheless, theoretical FEER models can include an endogenization of internal equilibrium that rests on the formulation of a wage-price dynamics in level terms. The price equation reflects the application of a mark-up to unit labour costs. The wage equation is derived from a bargaining process between unions and firms vested with the "right to manage" (R. Layard, S. Nickell, and R. Jackman 1991). The endogenization of internal equilibrium leads to an inverse causality between the real effective exchange rate and potential output. If a depreciation occurs, firms and workers have to share the rise in domestic prices caused by the deterioration in the terms of trade. If the workers refuse to absorb the full impact of the shock (and to accept a fall in their real income), the rise in the real cost of labour leads will cause firms to make a long-term reduction in their employment volume. When this happens, the equilibrium unemployment rate rises, lowering the potential-output level. This framework based on the bargaining process between unions and firms is regarded as an acceptable model for the industrial countries labour market, but it is not necessarily valid for emerging market economies. The problem will crop up again in calculating the level of potential output. Isard and Faruqee (1998) recommend computing domestic output gaps, which are not available for emerging countries, by using a Hodrick-Prescott filter. This is a practical way to deal with the issue of internal equilibrium. However, it is no clear that these procedure results in a real exchange rate that corresponds to internal balance of developing countries.

That is why we propose to develop an alternative approach, which re- 
lies on two sectors (tradables and nontradables) models of exchange rate behaviour. In this approach, the EER is defined as the internal exchange rate - the relative price of tradables to non-tradables -, which results in the simultaneous attainment of internal and external equilibrium. The main feature of this approach is that it allows for changes in the EER that results from the existence of non-traded goods and can thus describe the Balassa effect. Moreover, unlike BEER and FEER approaches, the concept of internal equilibrium is obvious: it is defined in terms of the equilibrium of nontradables market.

Two sectors models cover a range of theoretical frameworks, focusing generally on partial equilibrium models. These models rely on an extended PPP methodology and yield a negative correlation between relative prices and relative output across sector as to describe the Balassa effect. The specific mechanism that is relied upon to produce this effect is based on the following assumptions: the capital is mobile, both internationally and between sectors, and labour is free to migrate between sectors of an economy but not between countries. An important implication is that supply shocks affect both the equilibrium relative price and the relative production levels while demand shifts only affect the composition of output. The relevant fundamental of the real exchange rate identified here is the rate of growth in total factor productivity. Other models, by contrast, have focused on demand side explanations of the EER behaviour. Among such explanations, a factor often mentioned relates to the Baumol-Bowel effect: if productivity in the good's sector grows faster than in the service sector, the relative price of services would rise over time if demand for services is more income elastic. Since services and goods are concentrated respectively in the nontradables sector and in the tradable sector, such an effect could lead to an appreciation of the EER. De Gregorio, Giovanni and Wolf (1994) have developed a general equilibrium framework where the EER behaviour is explained by both supply side and demand side variables. However, as their model focus only on one period, it can't explain the time paths of the equilibrium exchange rate. Moreover, details on the methodology, as the formulation of microeconomic behaviours underlying the determination of the equilibrium exchange rate, are not clearly explicated.

In this framework, we seek to extend the general equilibrium framework of the equilibrium exchange rate behaviour on two tracks. First, we develop an analytical model that is intended to identify a set of supply side and demand side variables that affect the equilibrium exchange rate and to 
explore the direction of their influence on the EER. The second extension is that the model is implemented on two periods as to analyse the time path of the equilibrium exchange rate. The paper is organised as follows: the first section describes the analytical framework and how the model can be solved for the EER, considering exclusively one period. Then the second section expands the analysis to two periods. This extension allows us to consider the time path of the EER and describe how exchanges in exogenous variables affect the equilibrium value of the exchange rate.

\section{A one-period model}

In models based on the Balassa-Samuelson effect, the equilibrium exchange rate is determined exclusively by supply side variables and is independant of the economy's demand side. As international capital mobility is perfect and labor is mobile within the economy, supply-side is fully elastic and demand shifts doesn't affect the relative price of traded goods. A price inelastic supply is thus a neccesary condition for an effect of demand side variables on the real exchange rate (De Gregorio, Giovannini and Wolf, 1994).

In this section, we consider a general equilibrium framework where we relax the assumption of perfect capital mobility and add household's behavior. This allows us to consider not only supply side but also demand side determinants of the equilibrium exchange rate. We suppose also that trade desequilibrium are possible to a certain extend: trade deficits must be sustainable in medium or lung run, that is to say consistent with a rule of stabilizating the debt-to-GDP ratio. This assumption allows us to identify an other fundamental of the equilibrium exchange rate : the trade deficit target.

We consider a small open economy that produces two goods, tradables and non tradables. Outputs are given by diminishing returns production fonctions of the capital and the labor employed,

$$
\begin{gathered}
F_{T}\left(L_{T}, K_{T}\right)=A_{T} L_{T}^{\alpha} K_{T}^{\beta} \\
F_{N}\left(L_{N}, K_{N}\right)=A_{N} L_{N}^{\alpha} K_{N}^{\beta}
\end{gathered}
$$

with $\alpha+\beta<1$ 
where subscript $T$ denotes the traded sector, subscript $N$ the nontraded sector, and $A$ 's are productivity coefficients.

Labor is internationnaly immobile but can migrate between sectors within the economy. Labor mobility ensures that workers earn the same wage $\bar{w}$ in either sector. The total domestic labor supply and capital supply are fixed at $L_{T}+L_{N}=1$ and $K_{T}+K_{N}=1$

Firms maximise the value of profits:

$$
\max \left\{p_{T} F_{T}\left(L_{T}, K_{T}\right)+p_{N} F_{N}\left(L_{N}, K_{N}\right)-\bar{w}\left(L_{T}+L_{N}\right)-\bar{c}\left(K_{T}+K_{N}\right)\right\}
$$

The solution for this problem is:

$$
K_{T}=L_{T}=\frac{(e a)^{\frac{1}{1-\alpha-\beta}}}{1+(e a)^{\frac{1}{1-\alpha-\beta}}}
$$

with $e=\frac{p_{T}}{p_{N}}$, the equilibrium real exchange rate (a rise in $e$ means a real depreciation) and $a=\frac{A_{T}}{A_{N}}$.

Production fonctions then imply the following level of output in each sector:

$$
\begin{gathered}
Y_{T}=A_{T} L_{T}^{\alpha} K_{T}^{\beta}=A_{T}\left[\frac{(e a)^{\frac{1}{1-\alpha-\beta}}}{1+(e a)^{\frac{1}{1-\alpha-\beta}}}\right]^{\alpha+\beta} \\
Y_{N}=A_{N} L_{N}^{\alpha} K_{N}^{\beta}=A_{N}\left[\frac{1}{1+(e a)^{\frac{1}{1-\alpha-\beta}}}\right]^{\alpha+\beta}
\end{gathered}
$$

We suppose that trade desequilibrium are possible. We define the trade balance target in GDP points by $\lambda$ :

$$
p_{T}\left(M_{T}-X_{T}\right)=\lambda\left(p_{T} Y_{T}+p_{N} Y_{N}\right)
$$

with : $\lambda>0$, trade deficit target in GDP points; $M_{T}$ and $X_{T}$ are respectively import and export volumes of tradable goods. By definition, only tradable goods are imported or/and exported.

We consider the deficit trade as an additional income for households. Then consumption must be chosen subject to the following budget contraint: 


$$
p_{T} C_{T}+p_{N} C_{N}+p_{T} X_{T}=p_{T} Y_{T}+p_{N} Y_{N}+p_{T} M_{T}
$$

The budget contraint can be written as:

$$
p_{T} C_{T}+p_{N} C_{N}=(1+\lambda)\left(p_{T} Y_{T}+p_{N} Y_{N}\right)
$$

The consumer maximizes an utility function of the following form:

$$
\max \left\{\log C_{T}+\zeta \log C_{N}\right\}
$$

$\zeta$ is the preference parameter for non-tradable good.

We obtain the demand functions for tradables and non tradables,

$$
\begin{gathered}
C_{T}=\frac{1+\lambda}{1+\zeta} \frac{p_{T} Y_{T}+p_{N} Y_{N}}{p_{T}} \\
C_{N}=\frac{\varphi(1+\lambda)}{1+\zeta} \frac{p_{T} Y_{T}+p_{N} Y_{N}}{p_{N}}
\end{gathered}
$$

The market for traded and nontraded goods are in equilibrium if:

$$
\begin{gathered}
C_{T}+X_{T}=Y_{T}+M_{T} \\
C_{N}=Y_{N}
\end{gathered}
$$

which finally imply the equilibrium value for the internal exchange rate:

$$
(e a)^{\frac{1}{1-\alpha-\beta}}=\frac{1-\zeta \lambda}{\zeta(1+\lambda)}
$$

with: $\frac{\partial e}{\partial a}<0, \frac{\partial e}{\partial \zeta}<0$ and $\frac{\partial e}{\partial \lambda}<0$

In this model, it may be noted that the equilibrium exchange rate $(e)$ depends not only on technological conditions in the two sectors (variable $a$ ). It also depends on the demand parameter $\zeta$, that measures the individual's preference to consume nontradables and on $\lambda$, the trade deficit target.

We obtain a negative link between faster productivity in the tradable goods sector and the equilibrium exchange rate. This negative link represents the Balassa effect. The effect of a rise in the individual's preference to consume nontradables on the equilibrium real exchange rate is also straightforward: an increase in the preference parameter increases the 
consumption of nontradables and hence an appreciation of the equilibrium exchange rate. The price of nontradables increases when the output of tradables remains unchanged. Finally, a rise in the parameter $\lambda$, that is a worsening of the trade deficit, can be interpreted as a positive income effect. This income effect leads consumers to raise consumption in tradables and nontradables. The consumption's increase is matched by a an increase in imports that keeps the price of tradables constant, but increases the price of non tradables. Thus, the equilibrium real exchange rate appreciate.

Until now, we have simplified the analysis by assuming one single period. This assumption has usefully focused attention on the supply and demand factors determining the level of the equilibrium exchange rate. We extend the model to two periods to describe the equilibrium path of the equilibrium exchange rate.

\section{The two-period model}

In this model there is one consumer who lives for two periods. His utility function is

$$
u\left(c_{T}^{1}, c_{N}^{1}, c_{T}^{2}, c_{N}^{2}\right)=\left[\log \left(c_{T}^{1}\right)+\zeta \log \left(c_{N}^{1}\right)\right]+\delta\left[\log \left(c_{T}^{2}\right)+\zeta \log \left(c_{N}^{2}\right)\right]
$$

where $c_{T}^{i}, c_{N}^{i}$ denote respectively the consumptions of tradable and nontradable goods at period $i$. The parameters $\zeta, \delta$ are respectively the preference parameter for non-tradable good and the time preference parameter.

Her intertemporal income is

$$
R=p_{T}^{1} Y_{T}^{1}+p_{N}^{1} Y_{N}^{1}+p_{T}^{1}\left(M_{T}^{1}-X_{T}^{1}\right)+\frac{1}{1+r}\left(p_{T}^{2} Y_{T}^{2}+p_{N}^{2} Y_{N}^{2}+p_{T}^{2}\left(M_{T}^{2}-X_{T}^{2}\right)\right)
$$

where $p_{T}^{i}, p_{N}^{i}$ are tradable goods and non-tradable goods prices at period $i, r$ is the exogenous interest rate, $Y_{T}^{i}, Y_{N}^{i}$ are the productions of tradable goods and non-tradable goods at period $i$, and $M_{T}^{i}, X_{t}^{i}$ are the importations and exportations of tradable goods (we recall that only tradable goods are imprted or/and exported). We also suppose that the tradable goods prices $p_{t}^{1}, p_{t}^{2}$ are exogenous (imposed by the international market).

The consumer solves the program:

$$
\max u\left(c_{T}^{1}, c_{N}^{1}, c_{T}^{2}, c_{N}^{2}\right)
$$


under the constraints:

$$
p_{T}^{1} c_{T}^{1}+p_{N}^{1} c_{N}^{1}+\frac{1}{1+r}\left[p_{T}^{2} c_{T}^{2}+p_{N}^{2} c_{N}^{2}\right] \leq R
$$

We obtain

$$
\begin{aligned}
c_{T}^{1} & =\frac{1}{(1+\zeta)(1+\delta)} \frac{R}{p_{T}^{1}} \\
c_{T}^{2} & =\frac{\delta(1+r)}{(1+\zeta)(1+\delta)} \frac{R}{p_{T}^{2}} \\
c_{N}^{1} & =\frac{\zeta}{(1+\zeta)(1+\delta)} \frac{R}{p_{N}^{1}} \\
c_{N}^{2} & =\frac{\zeta \delta(1+r)}{(1+\zeta)(1+\delta)} \frac{R}{p_{N}^{2}}
\end{aligned}
$$

There is one firm which jointly produces tradable and non-tradable goods. We suppose that wages and capital good prices are exogenous and the capital depreciation rate equals 1 . So, firm maximizes at each period its profit. At period $i$, its demands for labor and capital inputs $L_{T}^{i}, L_{N}^{i}, K_{T}^{i}, K_{N}^{i}$ are solutions to the problem:

$$
\max \left\{p_{T}^{i} F_{T}\left(L_{T}^{i}, K_{T}^{i}\right)+p_{N}^{i} F_{N}\left(L_{N}^{i}, K_{N}^{i}\right)-\bar{w}\left(L_{T}^{i}+L_{N}^{i}\right)-\bar{c}\left(K_{T}^{i}+K_{N}^{i}\right)\right\} \ldots
$$

We assume that

$$
F_{T}(L, K)=A_{T} L^{\alpha} K^{\beta}
$$

and

$$
F_{N}(L, K)=A_{N} L^{\alpha} K^{\beta}
$$

with $\alpha+\beta<1, \alpha>0, \beta>0$.

We define

$$
a=\frac{A_{T}}{A_{N}}
$$

and at period $i$, the equilibrium exchange rate $e_{i}$ by

$$
e_{i}=\frac{p_{T}^{i}}{p_{N}^{i}}
$$


It is easy to find that the demands for labor and capital satisfy the following relations for every period $i$ :

$$
\begin{aligned}
& e_{i} a\left(\frac{K_{N}^{i}}{K_{T}^{i}}\right)^{1-\beta}\left(\frac{L_{T}^{i}}{L_{N}^{i}}\right)^{\alpha}=1, \\
& e_{i} a\left(\frac{K_{N}^{i}}{K_{T}^{i}}\right)^{-\beta}\left(\frac{L_{T}^{i}}{L_{N}^{i}}\right)^{\alpha-1}=1 .
\end{aligned}
$$

The productions of tradable and non tradable goods at period $i$ are:

$$
\begin{gathered}
Y_{T}^{i}=A_{T}\left(L_{T}^{i}\right)^{\alpha}\left(K_{T}^{i}\right)^{\beta}, \\
Y_{N}^{i}=A_{N}\left(L_{N}^{i}\right)^{\alpha}\left(K_{N}^{i}\right)^{\beta} .
\end{gathered}
$$

We assume that all the markets clear. We also assume that labor and physical capital supplies are exogenous.

We have

$$
\begin{gathered}
c_{N}^{1}=Y_{N}^{1}, \\
c_{N}^{2}=Y_{N}^{2}, \\
c_{T}^{1}+X_{T}^{1}=Y_{T}^{1}+M_{T}^{1}, \\
c_{T}^{2}+X_{T}^{2}=Y_{T}^{2}+M_{T}^{2}, \\
K_{T}^{1}+K_{N}^{1}=1, \\
K_{T}^{2}+K_{N}^{2}=1, \\
L_{T}^{1}+L_{N}^{1}=1, \\
L_{T}^{2}+L_{N}^{2}=1 .
\end{gathered}
$$

We refer to equations $(25), \ldots,(32)$ for the internal equilibrium. For the external equilibrium, we impose the following relation: 


$$
p_{T}^{1}\left(M_{T}^{1}-X_{T}^{1}\right)+\frac{1}{1+r} p_{T}^{2}\left(M_{T}^{2}-X_{T}^{2}\right)=\frac{\lambda}{1+r}\left[p_{T}^{2} Y_{T}^{2}+p_{N}^{2} Y_{N}^{2}\right] .
$$

The parameter $\lambda$ is exogenous. It expresses the norm of the deficit over GNP.

Proposition 1 (Existence of unique equilibrium exchange rates)

Assume $\lambda \delta<\frac{1+\delta}{\zeta}$. Then the equilibrium exchange rates $e_{1}, e_{2}$ are unique.

Proof. is easy to check that for every date $i$ :

$$
\begin{aligned}
& Y_{T}^{i}=A_{T}\left[\frac{\left(e_{i} a\right)^{\frac{1}{1-\alpha-\beta}}}{1+\left(e_{i} a\right)^{\frac{1}{1-\alpha-\beta}}}\right]^{\alpha+\beta}, \\
& Y_{N}^{i}=A_{N}\left[\frac{1}{1+\left(e_{i} a\right)^{\frac{1}{1-\alpha-\beta}}}\right]^{\alpha+\beta} .
\end{aligned}
$$

We also have

$$
\begin{gathered}
c_{T}^{1}=\frac{1}{(1+\zeta)(1+\delta)}\left[Y_{T}^{1}+\frac{Y_{N}^{1}}{e_{1}}+\tau \frac{1+\lambda}{1+r}\left(Y_{T}^{2}+\frac{Y_{N}^{2}}{e_{2}}\right)\right], \\
c_{T}^{2}=\frac{\delta}{(1+\zeta)(1+\delta)}\left[\frac{1+r}{\tau}\left(Y_{T}^{1}+\frac{Y_{N}^{1}}{e_{1}}\right)+(1+\lambda)\left(Y_{T}^{2}+\frac{Y_{N}^{2}}{e_{2}}\right)\right], \\
c_{N}^{1}=\frac{\zeta}{(1+\zeta)(1+\delta)}\left[\left(e_{1} Y_{T}^{1}+Y_{N}^{1}\right)+\frac{1+\lambda}{1+r} \tau e_{1}\left(Y_{T}^{2}+\frac{Y_{N}^{2}}{e_{2}}\right)\right], \\
c_{N}^{2}=\frac{\delta \zeta}{(1+\zeta)(1+\delta)}\left[\frac{1+r}{\tau} e_{2}\left(Y_{T}^{1}+\frac{Y_{N}^{1}}{e_{1}}\right)+(1+\lambda) e_{2}\left(Y_{T}^{2}+\frac{Y_{N}^{2}}{e_{2}}\right)\right],
\end{gathered}
$$

where $\tau=\frac{p_{T}^{2}}{p_{T}^{1}}$.

We obtain

$$
\frac{c_{N}^{1}}{c_{N}^{2}}=\frac{1}{\delta(1+r)} \frac{e_{1}}{e_{2}} \tau
$$




$$
\frac{Y_{N}^{1}}{Y_{N}^{2}}=\left[\frac{1+\left(e_{2} a\right)^{\frac{1}{1-\alpha-\beta}}}{1+\left(e_{1} a\right)^{\frac{1}{1-\alpha-\beta}}}\right]^{\alpha+\beta} .
$$

From equations (25),(26), we have:

$$
\frac{e_{1} a}{e_{2} a} \frac{\tau}{\delta(1+r)}=\left[\frac{1+\left(e_{2} a\right)^{\frac{1}{1-\alpha-\beta}}}{1+\left(e_{1} a\right)^{\frac{1}{1-\alpha-\beta}}}\right]^{\alpha+\beta},
$$

or equivalently

$$
\psi\left(x_{1}\right)\left(\frac{\tau}{\delta(1+r)}\right)=\psi\left(x_{2}\right),
$$

with $\psi(x)=x^{1-\alpha-\beta}(1+x)^{\alpha+\beta}$ which is an increasing function, and $x_{i}=\left(e_{i} a\right)^{\frac{1}{1-\alpha-\beta}}$.

We have

$$
\psi^{\prime}(x)=(\alpha+\beta)\left(\frac{x}{1+x}\right)^{1-\alpha-\beta}+(1-\alpha-\beta)\left(\frac{1+x}{x}\right)^{\alpha+\beta},
$$

and

$$
\psi^{\prime \prime}(x)=(\alpha+\beta)(1-\alpha-\beta)\left(\frac{1+x}{x}\right)^{\alpha+\beta-1} \frac{1}{x}\left(\frac{1}{1+x}-\frac{1}{x}\right)<0 .
$$

Hence, $\psi$ is concave.

Now consider equation (33). Replacing $c_{T}^{i}, c_{N}^{i}$ by their formula, we obtain:

$$
\zeta\left(Y_{T}^{1}+\frac{\tau(1+\lambda)}{1+r} Y_{T}^{2}\right)=\frac{Y_{N}^{1}}{e_{1}}+\frac{\tau}{1+r} \frac{Y_{N}^{2}}{e_{2}}(1-\lambda \zeta) .
$$

Replace $Y_{T}^{i}, Y_{N}^{i}$ by their expressions given by equations (34),(35), we obtain:

$$
\left(e_{1} a\right)^{\frac{1}{1-\alpha-\beta}}+\delta(1+\lambda)\left(e_{2} a\right)^{\frac{1}{1-\alpha-\beta}}=\frac{1+\delta}{\zeta}-\lambda \delta
$$

or

$$
x_{1}+\delta(1+\lambda) x_{2}=\frac{1+\delta}{\zeta}-\lambda \delta,
$$

with, as above, $x_{i}=\left(e_{i} a\right)^{\frac{1}{1-\alpha-\beta}}$. We have from equations (36), and (37): 


$$
\psi\left(x_{2}\right)=\left(\frac{\tau}{\delta(1+r)}\right) \psi\left(\frac{1+\delta}{\zeta}-\lambda \delta-\delta(1+\lambda) x_{2}\right)
$$

The first member of equation (38) is increasing in $x_{2}$ while the second member is increasing. Moreover, since $\psi(0)=0<\left(\frac{\tau}{\delta(1+r)}\right) \psi\left(\frac{1+\delta}{\zeta}-\lambda \delta\right)$, and $\psi\left(\frac{1+\delta-\zeta \lambda \delta}{\zeta \delta(1+\lambda)}\right)>\psi(0)$, there exists a unique solution to equation (38).

Proposition 2 Assume as before that $\lambda \delta<\frac{1+\delta}{\zeta}$. Then

(1) When a increases, the equilibrium exchange rates are lower for every period.

(2) When the interest rate increases, then the equilibrium exchange rate of the first period increases, and it decreases at the second period.

(3) If $\zeta$ increases (the consumer prefers more the non-tradable goods) then the equilibrium exchange rates become lower for the two periods.

(4) If $\lambda$ increases (the norm of deficit is higher), then the the equilibrium exchange rates become lower for the two periods.

(5) Strengthen condition $\lambda \delta<\frac{1+\delta}{\zeta}$ in $\lambda<\frac{1}{\zeta}$. If we increase $\delta$ (the consumer prefers more the future), then the equilibrium exchange rate increases at the first period and decreases at the second period.

Proof. The solutions $\left(x_{1}, x_{2}\right)=\left(e_{1} a, e_{2} a\right)$ depend only on the parameters $\lambda, \delta, \zeta, \tau, r$. Hence, if $a$ increases, then $e_{1}, e_{2}$ decreases.

(2) Differentiate equations (37), (38) with respect to $x_{1}, x_{2}$ and $r$. We then obtain

$$
\begin{gathered}
d x_{1}+\delta(1+\lambda) d x_{2}=0 \\
{\left[\psi^{\prime}\left(x_{1}\right)\left(\frac{\tau}{\delta(1+r)}\right) \delta(1+\lambda)+\psi^{\prime}\left(x_{2}\right)\right] d x_{2}=-\left(\frac{\tau}{\delta(1+r)^{2}}\right) \psi\left(x_{1}\right) d r}
\end{gathered}
$$

Obviously $\frac{\partial x_{1}}{\partial r}>0, \frac{\partial x_{2}}{\partial r}<0$.

(3) Differentiate equation (38):

$$
\left[\psi^{\prime}\left(x_{2}\right)+\frac{\tau(1+\lambda)}{(1+r)} \psi^{\prime}\left(x_{1}\right)\right] d x_{2}=-\frac{(1+\delta) \tau}{\delta \zeta^{2}(1+r)} \psi^{\prime}\left(x_{1}\right) d \zeta
$$


Differentiate equation (36):

$$
\psi^{\prime}\left(x_{1}\right)\left(\frac{\tau}{\delta(1+r)}\right) d x_{1}=\psi^{\prime}\left(x_{2}\right) d x_{2} .
$$

It is obvious that $\frac{\partial x_{2}}{\partial \zeta}<0, \frac{\partial x_{1}}{\partial \zeta}<0$.

(4) Differentiate equations (36), (38). Then

$$
\psi^{\prime}\left(x_{1}\right)\left(\frac{\tau}{\delta(1+r)}\right) d x_{1}=\psi^{\prime}\left(x_{2}\right) d x_{2},
$$

and

$$
\left[\psi^{\prime}\left(x_{2}\right)+\frac{\tau(1+\lambda)}{(1+r)} \psi^{\prime}\left(x_{1}\right)\right] d x_{2}=-\frac{\tau}{1+r}\left(1+x_{2}\right) d \lambda .
$$

Hence, $\frac{\partial x_{2}}{\partial \lambda}<0, \frac{\partial x_{1}}{\partial \lambda}<0$.

(5) Differentiate equations (37), (38). Then

$$
d x_{1}+\delta(1+\lambda) d x_{2}=0
$$

and

$$
\left[\psi^{\prime}\left(x_{2}\right)+\frac{\tau(1+\lambda)}{(1+r)} \psi^{\prime}\left(x_{1}\right)\right] d x_{2}=\frac{\psi\left(x_{1}\right)}{\delta(1+r)} d \tau .
$$

We obtain $\frac{\partial x_{2}}{\partial \tau}>0$ and $\frac{\partial x_{1}}{\partial \tau}<0$.

(6) Differentiate as before equation (38):

$$
\left[\psi^{\prime}\left(x_{2}\right)+\frac{\tau(1+\lambda)}{(1+r)} \psi^{\prime}\left(x_{1}\right)\right] d x_{2}=\frac{\tau}{\delta(1+r)}\left[-\frac{1}{\delta} \psi\left(x_{1}\right)+\left(\frac{1}{\zeta}-\lambda-(1+\lambda) x_{2}\right) \psi^{\prime}\left(x_{1}\right)\right] d \delta .
$$

Since $\psi^{\prime \prime}<0$, we have

$$
\psi\left(x_{1}\right)-\psi\left(\frac{1}{\zeta}\right)>\psi^{\prime}\left(x_{1}\right)\left(x_{1}-\frac{1}{\zeta}\right)=\psi^{\prime}\left(x_{1}\right)\left(\frac{\delta}{\zeta}-\lambda \delta-\delta(1+\lambda) x_{2}\right)
$$

Hence

$$
0>-\frac{1}{\delta} \psi\left(\frac{1}{\zeta}\right)>-\frac{\psi\left(x_{1}\right)}{\delta}+\left(\frac{1}{\zeta}-\lambda-(1+\lambda) x_{2}\right) \psi^{\prime}\left(x_{1}\right) .
$$

Therefore $\frac{\partial x_{2}}{\partial \delta}<0$. 
Now differentiate equation (37). We obtain

$$
d x_{1}=\left(\frac{1}{\zeta}-\lambda\right) d \delta-\delta(1+\lambda) d x_{2}
$$

We conclude that $\frac{\partial x_{1}}{\partial \delta}>0$.

The objective of this paper has been to analyse the determination of the level and the time path of the equilibrium exchange rate in the context of a simple general equilibrium framework based on two sectors and two periods. The equilibrium exchange rate was defined as the real exchange rate consistent with internal equilibrium (in terms of nontradables market equilibrium) and external equilibrium (in terms of sustainable trade balance). This model has allowed us to identify several determinants of the level and the time path of equilibrium exchange rate: supply-side factors, demandside sectors and the trade deficit target. In particular, the appreciation of the equilibrium exchange rate over the two periods can be explained by a productivity shock in the traded-goods sector (Balassa effect), a rise in the individual's preference to consume nontradables and a rise in the trade deficit target.

\section{Bibliography}

Balassa, Bela: (1964) : "The Purchasing Power Parity : a Reappraisal ", Journal of Political Economy, vol 72, issue 6, pp. 584-596.

Borowski, Didier \& Couharde, Cécile (2003): "The Exchange Rate Macroeconomic Balance Approach: New Methodology and Results for the Euro, the Dollar, the Yen and the Pound Sterling", Open economies review 14.

Clark, Peter \& MacDonald, Ronald (1999) : " Exchange rates and economic fundamentals : a methodological Comparison of BEERs and FEERs ", in Ronald MacDonald and Jerome Stein (ed.), Equilibrium Exchange Rate, Kluwer Academic Publishers.

Coudert, Virginie \& Couharde, Cécile (2003) : " Exchange rate regimes and sustainable parities for CEECs in the run-up to EMU membership ", Revue économique, vol. 54, $\mathrm{n}^{\circ} 5$, September.

De Gregorio, José, Alberto Giovannini, Holger Wolf (1994) : " International evidence on tradables and non tradables inflation ", European Economic Review 38, pp. 1225-1244. 
Edwards, Sebastian (1994) : " Real and monetary determinants of real Exchange rate behavior : theory and evidence from developing countries", in Williamson, ed (1994).

Elbadawi Ibrahim (1994): " Estimating Long Run Equilirium Real Exchange Rates", in Williamson, ed (1994).

Faruqee, Hamid (1995) : " Long-run determinants of the real exchange rate : a stock-flow perspective", IMF Staff Papers, vol $42, n^{\circ} 1$, mars, pp $80-107$.

Isard, Peter \& Faruqee, Hamid (1998) Exchange Rate Assessment - Extensions of the Macroeconomic Balance Approach, IMF Occasional Paper no. 167 .

Montiel, Peter (1999)" Determinants of the Long Run Equilibrium Real Exchange Rate : An Analytical Model", in Lawrence Hinkle and Peter Montiel " Exchange Rate Misalignments", Oxford University Press, 1999.

Stein, Jerome (1994) : "The Natural Real Exchange Rate of the US Dollar and Determinants of Capital Flows", in Williamson, ed (1994).

Williamson, John (1994), ed, " Estimating Equilibrium exchange rate ", Institute for International Economics, Washington.

Wren-Lewis, S. \& Driver, R. (1998), Real Exchange Rates for Year 2000, Institute for International Economics, Washington. 